\title{
Hegemonia heterossexista, lutas antipatriarcais e partido político: introdução ao debate teórico
}

\author{
Leonardo Nogueira Alves ${ }^{1}$
}

Resumo: Este artigo vislumbra compreender, no âmbito das lutas de classes, o papel das lutas de caráter antipatriarcal e sua relação com a função do partido político da classe trabalhadora. Partimos da perspectiva de que as relações patriarcais de gênero, hegemônicas em nossa sociedade, são fundamentadas e retroalimentadas pela dinâmica do heterossexismo. Assim, por meio de uma reflexão teórica, explicitamos o significado das lutas antipatriarcais, os seus limites e desafios e o potencial do partido político como instrumento universalizante das lutas sociais.

Palavras-chave: Heterossexismo; Lutas de classes; Partido político.

Abstract: The purpose of this article is the class struggle's compression, the role of antipatriarchal struggles and their relation to the function of the working class political party. We start from the perspective that the patriarchal gender relations, hegemonic in our society, are grounded and fed by the dynamics of heterosexism. Then, through a theoretical reflection, we explain the meaning of antipatriarchic struggles, their limits and challenges and the potential of the political party as a universal instrument of social struggles.

Keywords: Heterossexism; Class struggles; Political party.

\footnotetext{
${ }^{1}$ Professor substituto na Faculdade de Serviço Social da Universidade Federal de Juiz de Fora. E-mail: leo.ssoufvjm@gmail.com.
} 


\title{
Introdução
}

\author{
Restará de nós \\ algo mais que o gesto ou a palavra: \\ esse desejo candente de liberdade, \\ Essa intoxicação, \\ contagiam-se! \\ Gioconda Belli²
}

A sociabilidade capitalista, ao tornar-se hegemônica, ocupou todas as esferas da vida social ao ponto de, em decorrência do ímpeto expansionista tão característico deste modo de produção, já não existir relação social que não esteja imersa nas legalidades e constrições próprias do capitalismo contemporâneo. Expressão disso é o fato de que, sob a égide desse modo de produção, as relações de dominação/ exploração em decorrência do gênero, da sexualidade e da "raça"/ etnia são reeditadas obedecendo às necessidades de maior controle e exploração do capital.

No capitalismo, as diferenças são transformadas em desigualdades e, recorrentemente, utilizadas para justificar e naturalizálas, sem questionar os seus fundamentos. A complexidade desse processo leva-nos a perceber que, na sociedade capitalista é impossível construir a plena igualdade entre sujeitos portadores de diferenças que deveriam ser apreendidas como componente da diversidade humana.

Partimos da compreensão de que o patriarcado, o racismo e o capitalismo se relacionam de forma recíproca, ou, nos termos cunhados por Saffioti (2004), patriarcado-racismo-capitalismo formam um "novelo" que permite certa mobilidade entre estas formas de dominação, porém nenhum destes pode prescindir dos demais.

${ }^{2}$ BELLI, G. Restará de nós. In: . O olho da mulher. Diamantina: Arte Desemboque, 2012.

$220 \quad$ Hegemonia heterossexista, lutas antipatriarcais... 
$\mathrm{Na}$ elaboração das feministas materialistas francófonas, as relações sociais de sexo, "raça"/etnia e classe são consubstancias e coextensivas, conforme destaca análises de Kergoat (2010), Falquet (2008, 2013) e Devreux (2011). Ou seja, se estas relações são indissociáveis, os projetos históricos que vislumbram a possibilidade de ruptura com a ordem social capitalista deve pressupor o enfrentamento ao patriarcado e ao racismo.

O nosso ponto de partida é a compreensão de que existem características heterossexistas que fundamentam e retroalimentam as relações patriarcais de gênero. ${ }^{3}$ Sendo assim, a compreensão de que existem relações de gênero determinadas pelo desenvolvimento do patriarcado implica, necessariamente, um olhar para o modo como os homens e as mulheres vivenciam a sua sexualidade. A partir disso, buscaremos dialogar com processos históricos de resistência ao capitalismo-patriarcal, caracterizados como "lutas antipatriarcais".

Realizaremos neste artigo uma análise teórica da hegemonia heterossexista e uma caracterização das lutas antipatriarcais na sociedade capitalista. Em seguida, faremos alguns apontamentos sobre a importância do partido político como mediador universal das lutas sociais. Com isso, objetivamos, de modo introdutório, estabelecer um diálogo em construção sobre a importância dos partidos políticos que vislumbram a construção de uma sociedade emancipada -

\footnotetext{
${ }^{3}$ A noção de relações patriarcais de gênero utilizada neste artigo é parte de um esforço próprio de sistematização e diálogo com a compreensão de patriarcado largamente utilizada por Heleieth Saffioti $(1987,2004)$ e pelo acúmulo do debate feminista materialista expresso, sobretudo, nas formulações de Danièle Kergoat (2010), Jules Falquet (2008) e Anne-Marie Devreux (2011). O debate proposto neste artigo se vale do acúmulo destas duas perspectivas de análise que não julgamos como colidentes, embora tenham divergências objetivas como, por exemplo, a utilização do termo gênero, a noção de sistema e/ou relação social. Em nossa concepção, estas duas perspectivas buscam, a partir de um paradigma de totalidade, saturar de determinações materiais as relações de dominação/exploração vivenciadas por mulheres e pessoas não-heterossexuais. Parcela significativa desta nossa afirmação encontra-se em: NOGUEIRA, L. Relações patriarcais de gênero e Serviço Social no Brasil. 250 f. Dissertação (mestrado em Serviço Social). Faculdade de Serviço Social da Universidade do Estado do Rio de Janeiro, 2017.
}

cadernos cemarx, no $10-2017 \quad 221$ 
e livre das armadilhas capitalistas - incorporarem as lutas de caráter antipatriarcal como componente necessário para a emancipação do proletariado.

\section{A dimensão heterossexista das relações patriarcais de gênero}

A sexualidade é parte fundamental da vida humana e sempre foi uma experiência integrante da sociabilidade entre homens e mulheres. Embora a compreensão da sexualidade implique o reconhecimento do fator orgânico/biológico inerente aos seres humanos, é nas determinações sociais que devemos compreender a forma pela qual homens e mulheres vivenciam sua sexualidade. Assim, compreendemos que a sexualidade é determinada pela forma como cada sociedade se organiza e se estrutura. Ou seja, existe um forte vínculo entre a sexualidade e as determinações sociais, políticas, econômicas e culturais de cada época, conforme sinalizam Prado e Machado (2009).

No entanto, embora a sexualidade seja uma parte fundamental da vida humana, esta tem sido tratada de forma reduzida à medida que inúmeras formas de controle impõem sobre a experiência sexual de homens e mulheres e padrões e normas a cerceiam (OKITA, 2015). ${ }^{4}$ A história da humanidade nos mostra que a vivência da sexualidade sempre foi profundamente diversa. Práticas hoje denominadas como heterossexualidade, homossexualidade e bissexualidade eram comuns em povos culturalmente diferentes e geograficamente distantes (STEARNS, 2010).

Ao longo do desenvolvimento histórico da humanidade engendraram-se relações desiguais entre homens e mulheres com base na divisão sexual do trabalho. A conformação das relações patriarcais

\footnotetext{
${ }^{4}$ Cornwall e Jolly (2008, p. 31), ressalvam que, "embora a sexualidade seja uma parte importante da vida das pessoas, essa rica e diversa experiência humana é, com demasiada frequência, reduzida a informações factuais, dados, alertas ameaçadores e instruções sobre o que não deve ser feito".
}

222 Hegemonia heterossexista, lutas antipatriarcais... 
de gênero na história implicou um controle sobre a sexualidade humana, com fortes restrições para as mulheres e o controle do sexo não reprodutivo. ${ }^{5}$ Assim, a ordem patriarcal de gênero impõe um modo de vida heterossexual aos homens e mulheres.

De acordo com Borrillo (2010, p. 31):

A heterossexualidade aparece, assim, como o padrão para avaliar todas as outras sexualidades. Essa qualidade normativa e o ideal que ela encarna - é constitutiva de uma forma específica de dominação, chamada heterossexismo, que se define como a crença na existência de uma hierarquia das sexualidades, em que a heterossexualidade ocupa a posição superior.

A sexualidade é naturalizada pelas relações patriarcais de gênero, como se fosse exclusivamente uma determinação biológica. ${ }^{6}$ Para Welzer-Lang (2001, p. 467), “o heterossexismo é a promoção incessante, pelas instituições e/ou indivíduos, da superioridade da heterossexualidade e da subordinação simulada da homossexualidade. O heterossexismo toma como dado que todo mundo é heterossexual". O heterossexismo organiza o modo pelo qual homens e mulheres vivem a sua sexualidade e, portanto, é um dos pilares fundamentais das relações patriarcais de gênero.

$\mathrm{O}$ heterossexismo atua engessando as fronteiras que foram definidas como papéis impostos aos homens e mulheres. Valendo-se de uma pretensa determinação natural, o heterossexismo extrapola

\footnotetext{
${ }^{5}$ De acordo com Stearns (2010), com a emergência das grandes civilizações como a Grécia, a China, a Roma, a Pérsia, e a Índia, cada sociedade estabeleceu um enfoque distintivo sobre os papeis de gênero e sexualidade, porém tais experiências sempre buscaram estabelecer restrições para o sexo não-reprodutivo.

6 Acerca da sexualidade, Lukács (2013, p. 174) afirma que “a atração sexual recíproca jamais perderá o seu caráter essencialmente corporal, biológico, mas com a intensificação das categorias sociais o relacionamento sexual acolhe cada vez mais conteúdos, que de fato alcançam uma síntese mais ou menos orgânica na atração física, mas que possuem em relação a esta um caráter - direta ou mediatamente - humanosocial heterogêneo".
} 
o mero controle da sexualidade. Ao contrário, atua para organizar o conjunto das relações sociais prescrevendo os modos de ser homem e de ser mulher necessários para a preservação das relações patriarcais de gênero.

Cabe destacar que há uma "lógica binária que serve de estrutura para a construção da identidade sexual [que] funciona por antagonismo: assim, o homem é o oposto da mulher, enquanto o heterossexual opõe-se ao homossexual" (BORRILLO, 2010, p. 88). O referido autor acrescenta que "o cúmulo da falta de virilidade consiste em assemelhar-se à feminilidade" (2010, p. 88). A personalidade masculina é construída em negação e oposição a personalidade feminina. $\mathrm{O}$ autor destaca que a construção do ser homem é permeada pelo reforço de uma "virilidade", demonstração de força, impossibilidade de demonstrar fraquezas e vulnerabilidades, contenção dos sentimentos etc. A virilidade é construída ao longo da formação dos meninos como um atributo a ser conquistado.

A vivência de relações não heterossexuais tem promovido diversas formas de preconceitos e discriminações, conforme discutido anteriormente. As expressões dessas formas de discriminação são conhecidas como homofobia, lesbofobia e bifobia. Tais construções também impactam a emergência da transfobia, que, embora seja decorrente da não-aceitação da identidade de gênero das pessoas trans e não necessariamente sua orientação sexual, tem como fundamento os desdobramentos do sexismo.

É importante ressaltar que há particularidades nas formas de manifestação da lesbofobia, que implica o peso histórico da invisibilidade da sexualidade das mulheres, como se não fosse possível duas mulheres se relacionarem sem um homem. Além disso, também é necessário perceber que esses fundamentos patriarcaisheterossexistas estão correlacionados com as relações étnico/raciais e de classe social.

224 Hegemonia heterossexista, lutas antipatriarcais... 


\section{As lutas "antipatriarcais": possibilidades e limites para construção de uma resistência anticapitalista}

É perceptível, na história moderna, que homens e mulheres desenvolveram várias formas de lutas, dentre as quais julgamos pertinentes explicitar aquelas decorrentes do movimento feminista e do movimento de lésbicas, gays, bissexuais, travestis e transexuais (LGBT). Tendo em vista a compreensão das características heterossexistas do patriarcado, julgamos que as lutas do movimento feminista e do movimento LGBT possuem um denominador comum: a resistência às relações patriarcais de gênero. Estes movimentos, resguardadas suas especificidades organizativas e opções políticas, conformam um campo de lutas que pode ser denominado como "antipatriarcal".

Na década de 1970 também surge no Brasil os primeiros grupos LGBT com caráter de movimento político sobre a questão da homossexualidade, dentre estes o Grupo SOMOS cuja parcela de militantes era vinculada à "Convergência Socialista", (atualmente o Partido Socialista dos Trabalhadores Unificado - PSTU). ${ }^{7}$ Os grupos que surgiam a partir daí tinham grande influência da conjuntura política brasileira, abarcando desde o impacto repressivo da ditadura até o ressurgimento das lutas de massa pela democratização da sociedade brasileira.

Nos anos 1980, os grupos LGBT começam a se articular em encontros, como por exemplo, o I Encontro de Grupos de Homossexuais Organizados e o I Encontro Brasileiro de Homossexuais. Nestes encontros haviam "vários simpatizantes de partidos políticos de esquerda, legais, como o recém-criado Partido dos Trabalhadores,

\footnotetext{
7 Cabe ressaltar, conforme Simões e Facchini (2009, p. 63) que "o movimento que surgiu no final dos anos 1970 não foi o primeiro esforço de articulação de pessoas em torno do interesse comum na homossexualidade no Brasil. Desde os anos 1950, ou até mesmo antes, encontramos nas grandes cidades formas de associação dedicadas à sociabilidade, à diversão, e à paródia, aglutinando principalmente homens, que promoviam eventos como concursos de miss, shows de travestis e desfiles de fantasia".
} 
ou clandestinos em via de legalização, como o PCB e o PC do B, além da Convergência Socialista, que naquele momento aderira ao $\mathrm{PT}^{\prime \prime}$ (SIMÕES; FACCHINI, 2009, p. 106).

Cabe destacar que na década de 1980 os países da América Latina vivenciavam as experiências de redemocratização que possibilitaram "uma ampliação dos espaços de participação politica e [...] uma ressignificação do conceito de sociedade civil" (GURGEL, 2010 , p. 18). No entanto, a conjuntura político-econômica dos anos 1980 e 1990 influenciaram fortemente os movimentos sociais, especialmente com a dinâmica do terceiro setor. Falquet (2003, p. 20) também explicita esse cenário avaliando criticamente as problemáticas que o movimento feminista estava imerso,

[...] apesar de las diferencias que existen de un país a otro, el movimiento feminista parece haberse transformando en un conjunto de ONGs profesionalizadas que se organizan en redes muy especializadas fuertemente dependientes de financiamientos externos, [...], mientras que la vida cotidiana de las mujeres (alimentación, educación, salud, vivienda, trabajo remunerado etc.) empeora dramáticamente bajo los efectos de la mundialización neoliberal-capitalista.

Apesar dos dilemas apontados por Gurgel (2010) e Falquet (2003), o movimento feminista a partir da década de 1990 experimentou avanços importantes no que diz respeito à experimentação de novas formas organizativas e inserção de novos sujeitos em suas lutas. Os movimentos sociais feministas e LGBT possuem um papel de extrema relevância no enfrentamento do patriarcado, assim como, a depender do conteúdo de suas pautas, do racismo e do capitalismo. Estas lutas cumprem uma função questionadora que pode ir além da capacidade de percepção dos próprios movimentos auto-organizados de mulheres e LGBT. Meszáros (2006, p. 223), por exemplo, afirma que o movimento feminista "vai muito além dos limites de suas necessidades imediatas; ele realmente questiona o âmago do sistema dominante de reprodução

226 Hegemonia heterossexista, lutas antipatriarcais... 
sociometabólica". Para esse autor, na ordem capitalista é impossível garantir a igualdade substantiva entre homens e mulheres.

No entanto, as lutas em torno destas bandeiras políticas (mulheres, negros/as, LGBT, juventude), têm sido caracterizadas pela fragmentação e pela ausência de bandeiras estruturais para o conjunto da sociedade. Ao avaliar o movimento LGBT, Vinagre (2011, p. 55) afirma que estes carecem de uma "consciência de classe nas suas reinvindicações, embora possam, potencialmente, contribuir para a construção da emancipação política e do projeto político de transformação societária". Para nós, mesmo carecendo de caráter classista, estas lutas contribuem de forma particular para adensar o debate da emancipação humana, pois nos levam a refletir sobre a dimensão de gênero e sexualidade na formação dos sujeitos que compõem a classe trabalhadora.

Vinagre (2011, p. 61) acrescenta ainda que

[...] as lutas particulares são necessárias e constituem mesmo uma mediação política estratégica entre a consciência individual alienada, produto da sociabilidade liberal/burguesa, as práticas de resistência voltadas à conquista e ampliação dos chamados direitos humanos, no plano da emancipação política, e à consciência revolucionária, que pode levar à superação da sociedade burguesa e à emancipação humana.

Desse modo, reconhecemos que as lutas particulares possuem potencial revolucionário à medida que estão articuladas e integradas aos projetos macrossociais da classe trabalhadora que referendam a luta anticapitalista. Assim, a luta antipatriarcal possui caráter revolucionário, desde que sintonizada com a dinâmica da luta de classe. Para isso, é imprescindível retomar a assertiva de Marx e Engels (2010, p. 41) ao perceberem que "a sociedade divide-se cada vez mais em dois campos opostos, em duas grandes classes em confronto direto: a burguesia e o proletariado". Na sociedade capitalista as classes sociais fundamentais (burguesia e proletariado) constituem o que 
há de mais intrínseco em relação à ordem burguesa. Dessa forma, as classes só existem em permanente antagonismo, sendo que a existência de uma pressupõe a dominação da outra.

Partimos do pressuposto de que, embora as classes sociais sejam determinantes em última instância do modo de produção e reprodução das relações sociais capitalistas, existem duas mediações que mesmo anteriores ao capitalismo cumpriram um papel fundamental para a instauração da ordem do capital: o patriarcado e o racismo. ${ }^{8}$

Para Saffioti (1987, p. 67), "esses três sistemas de dominaçãoexploração fundiram-se de tal maneira, que será impossível transformar um deles, deixando intactos os demais". Ou seja, a autora oferece insumos às lutas sociais que visam à emancipação da humanidade, pois nos esclarece que sem reconhecer o caráter deste "nó", é impossível derrotar este sistema de dominação-exploração, uma vez que "a concepção da simbiose patriarcado-racismo-capitalismo muda inteiramente a estratégia de luta das classes trabalhadoras" (SAFFIOTI, 1987, p. 94). A análise de Vinagre (2011, p. 59) reitera esta concepção: "para efetivação do projeto de emancipação humana é necessário, então, a luta concomitante [...] contra todas as formas de exploração e opressão, o que inclui contrapor-se a todas as formas de preconceito, discriminação, arbítrio e violência (simbólica e física)".

\footnotetext{
${ }^{8}$ Essa afirmação é fruto de uma tentativa de compreender a realidade social levando em consideração que a compreensão do caráter determinante que cumpre as relações de classe não deve escamotear outras formas de dominação/exploração advindas das relações patriarcais de gênero e do racismo. Por isso, ao buscarmos compreender a realidade numa perspectiva materialista histórica dialética, acreditamos que é salutar recuperar tanto o esforço teórico-político empreendido por Marx e Engels e pela tradição marxista quanto o acúmulo do leito histórico do feminismo que buscou apreender a opressão das mulheres numa ótica materialista. Cabe salientar que a "determinação de classe em última instância" não é um ponto consoante na elaboração feminista que utilizamos no presente artigo. No entanto, embora não haja uma homogeneidade nestas formulações, acreditamos que é possível afirmar a determinação de classe social e construir sínteses sem colocar em demérito estes estudos feministas.
}

228 Hegemonia heterossexista, lutas antipatriarcais... 
Com estas considerações é possível afirmar que o proletariado, ao incorporar a luta antirracista e antipatriarcal, potencializa e radicaliza o sentido da ação revolucionária que lhe cabe na ordem burguesa. No conjunto da elaboração de Marx e Engels é possível constatar o caráter revolucionário do proletariado à medida que só a classe proletária possui os interesses para destruir a opressão produzida pela ordem burguesa.

No entanto, essa perspectiva aludida anteriormente é profundamente tensionada pela conjuntura pós-1960. Inúmeras mudanças sociais, políticas, econômicas e culturais contribuíram para moldar novas formas de vivenciar o espaço e o tempo, sob a velha base de contradições impostas pelo capitalismo (HARVEY, 2012). Essas transformações desafiaram as teorias advindas da modernidade que se esforçavam em construir uma concepção mais universal sobre as relações sociais. Destarte, a "crise das ideologias, o proclamado fim das utopias, devido ao colapso do socialismo real nos países do leste europeu, e o questionamento dos paradigmas teóricos, políticos e históricos colocaram em debate o projeto da modernidade" (SIMIONATO, 2009, p. 5). Abre-se um cenário para adoção de caminhos alternativos para conhecer a realidade, produzir conhecimento, assim como novas formas de enfrentamento e lutas contra as diversas formas de opressão, que até então não eram abordadas nas organizações de esquerda tradicionais, tais como partidos e sindicatos.

Foi nesse contexto histórico que as lutas do movimento LGBT e do movimento feminista ganharam notoriedade política e acadêmica. Em alguma medida, esses movimentos foram identificados como forma alternativa de visão de homem/mundo e de organização, tendo em vista que estes debates não ecoavam nos partidos políticos e sindicatos, por exemplo. Muitos acusavam (e ainda acusam) a tradição marxista por cunhar uma concepção fechada sobre as classes sociais como expressão do antagonismo entre burguesia e proletariado, entre capital e trabalho. Teóricos como Santos (1996) percebem no avanço 
das lutas específicas, noutros termos, dos "novos movimentos sociais", os sinais de que o marxismo estava equivocado ao sugerir o proletariado como classe fundamental do processo de transformação social. Santos (1996), equivocadamente, identifica que com a emergência da pós-modernidade os "novos movimentos sociais" desempenham um papel cada vez mais central nos processo de transformação social. ${ }^{9}$ $\mathrm{Na}$ concepção de Santos (1996) estas mudanças representam a ruptura com o paradigma moderno, enquanto para Harvey (2012) representa uma reação ao modernismo que estava atrelado ao regime de acumulação e regulação fordista, ou seja, o pós-modernismo se configura como uma reação às novas configurações da produção, circulação e consumo.

Essas movimentações da conjuntura e seus impactos na produção do conhecimento e na luta de classe impactam diretamente a construção de um projeto revolucionário. Braz (2015, p. 22) destaca que, "essa dissolução analítica da possibilidade de um projeto global de superação da ordem dissolve igualmente, mas também no plano analítico, a disposição política e teórica para se reconstruir organizações políticas revolucionárias com o partido". Este cenário foi profundamente impactado pela crise do socialismo que, com a queda da antiga União das Repúblicas Socialistas Soviéticas (URSS), contribuiu politicamente e ideologicamente para legitimar a reestruturação produtiva e a ofensiva neoliberal.

$\mathrm{Na}$ "contracorrente" dessa conjuntura que desqualifica e torna oblíqua e difusa a construção de um projeto de emancipação que vislumbra superar a tríade capitalismo-patriarcado-racismo, constatamos a necessidade e a viabilidade do resgate do papel

\footnotetext{
${ }^{9} \mathrm{Na}$ concepção que desenvolvemos neste trabalho, não se trata de apreender as lutas dos movimentos sociais (especialmente os feministas, LGBT e antirracistas) como deslocados das lutas mais amplas da classe trabalhadora pela transformação social. A questão fundamental é o modo como elas se associam e se entrecruzam, afinal a classe trabalhadora é atravessada pelas marcas das relações patriarcais de gênero, de "raça"/etnia, de orientação sexual e identidade de gênero.
}

$230 \quad$ Hegemonia heterossexista, lutas antipatriarcais... 
do proletariado nas lutas contra a ordem social burguesa. A perspectiva que construímos até aqui, e que daremos prosseguimento, percebe o papel decisivo da luta antipatriarcal para que o proletariado possa lograr êxito em seu projeto estratégico.

Neste sentido, é salutar construir uma abordagem que perceba o potencial das resistências empreendidas pelas mulheres e pessoas LGBT associadas ao projeto de emancipação do proletariado. Essa análise precisa ultrapassar os limites das lutas específicas buscando retomar a centralidade do partido político como instrumento universalizante das lutas sociais (BRAZ, 2014), dentre estas as lutas de caráter antipatriarcal.

\section{O partido político como mediador universal e as lutas antipatriarcais}

Com estas considerações é possível afirmar que o proletariado ao incorporar a luta antirracista e antipatriarcal potencializa e radicaliza o sentido da ação revolucionária que lhe cabe na ordem burguesa. No conjunto da elaboração de Marx e Engels é possível constatar o caráter revolucionário do proletariado à medida que só a classe proletária possui os interesses para destruir a opressão produzida pela ordem burguesa.

Lukács (2012) ressalta, na esteira da tradição socialista, que o fundamento do papel revolucionário do proletariado deve ser percebido na própria posição social que esta classe ocupa na produção capitalista. Por isso, a transformação social da ordem capitalista não é um processo natural e/ou acidental. Ao contrário, deve-se levar em conta tanto as contradições das relações sociais de produção existentes (MARX, 2008) quanto o protagonismo do proletariado organizado (MARX; ENGELS, 2010).

Dessa forma, a revolução conduzida pela classe que vive da venda do seu próprio trabalho possui um caráter socialista e proletário. $\mathrm{Na}$ esteira do pensamento de Marx e Engels, Lênin desenvolve seus 
estudos a partir da realidade russa na transição do século XIX para o século XX, delineando a centralidade da tomada do poder do Estado para a concretização da revolução proletária e socialista. Para Lênin o proletariado só tem um interesse: levar até o fim a destruição das classes e tornar possível o definhamento do Estado. Noutros termos,

[...] os trabalhadores só tem necessidade do Estado para quebrar a resistência dos exploradores (...) o proletariado é a única classe revolucionária até o fim capaz de unir todos os trabalhadores e todos os explorados na luta contra a burguesia, a fim de suplantar definitivamente (LENIN, 2010, p. 44-45).

Para que a revolução seja viável é necessário que o proletariado esteja organizado suficientemente para enfrentar os desafios da luta de classes. Ou seja, o proletariado deve constituir-se como classe para construir estratégias que visam conquistar o poder político. O instrumento privilegiado para esse desafio é a organização partidária. De acordo com Braz (2011, p. 30) o partido, no pensamento de Marx e Engels, é compreendido como "o mais amplo instrumento de ação política do proletariado". Acrescenta ainda que, "o antagonismo central da sociedade capitalista entre capital e trabalho exige que se ergam mediadores das diversas demandas (de classe) que se apresentam na superficialidade dos fenômenos como demandas isoladas" (BRAZ, 2014, p. 148).

Marx e Engels não formularam uma definição exata do que seria o partido revolucionário. No entanto, Braz (2011) destaca que a partir da publicação do "Manifesto Comunista", redigido por Marx e Engels em 1848, todas as organizações de caráter comunista e socialista se orientaram a partir desta obra formulando, a partir de cada contexto e região, o caráter, a função e os objetivos das suas organizações.

As contribuições de Lenin foram primordiais no campo dos estudos sobre "teoria da organização política". Lukács (2012) reforça o pioneirismo de Lenin ao afirmar que por muito tempo ele foi o único líder e teórico a considerar o problema da organização.

232 Hegemonia heterossexista, lutas antipatriarcais... 
Na concepção desenvolvida por Lenin, o partido é instrumento político capaz de aglutinar os setores mais conscientes do proletariado de forma centralizada. Ou seja, o partido exerce uma função dirigente da classe operária. Lukács (2012) percebe que a centralidade da concepção de partido em Lenin consiste na sua função preparatória, ou seja, o partido precisa atuar de maneira intencional nas constrições da sociedade capitalista no intuito de acelerar a precipitação da ordem burguesa. Lukács destaca que na obra e na trajetória política de Lenin a concepção de organização está umbilicalmente ligada à perspectiva de revolução. Por isso, "a função do partido na preparação da revolução faz dele, ao mesmo tempo e com a mesma intensidade, produtor e produto, pressuposto e resultado dos movimentos revolucionários de massa" (LUKÁCS, 2012, p. 52).

Cabe destacar a compreensão do próprio Lenin, no livro "Que Fazer?", publicado originalmente em 1902, onde o autor explicita suas reflexões sobre os dilemas do proletariado e do partido social democrata russo poucos anos antes da Revolução Russa de 1917. Para Lenin, a revolução socialista é impensável sem um instrumento político (partido) que consiga dar coesão, imprimir intencionalidade e garantir a continuidade dos processos revolucionários.

Em síntese:

$\left.1^{\circ}\right)$ que não pode haver movimento revolucionário sólido sem uma organização estável de dirigentes, que assegure sua continuidade; $2^{\circ}$ ) que quanto maior for a massa espontaneamente integrada à luta, massa que constitui a base do movimento e nele participa, mais imperiosa será a necessidade de se ter tal organização, e mais sólida ela deverá ser [...] $3^{\circ}$ ) que tal organização deve ser composta, principalmente, de homens voltados profissionalmente às atividades revolucionárias (LENIN, 2015, p. 184-185).

Entretanto, a percepção do caráter universalizante e da potência peculiar do partido de caráter revolucionário tem sido duramente

cadernos cemarx, no $10-2017 \quad 233$ 
questionada, conforme sinalizamos no item anterior. $\mathrm{O}$ debate atual sinaliza para um descrédito da forma partido político como instrumento de organização e de luta. Atesta-se a sua falência como instrumento coletivo de transformação social ao dar ênfase às formas moleculares e fragmentárias de mobilização de setores da sociedade.

Esse cenário acompanha a processualidade da crise do movimento comunista mundial, mais especificamente do desmoronamento das experiências socialistas construídas no século XX. Tal crise envolve a dificuldade de legitimidade desses projetos, de construção e fortalecimento de uma base social e de definição estratégico-tática, ou seja, uma crise de projeto societário.

$\mathrm{Na}$ contracorrente da conjuntura atual influenciada pelos particularismos e modismos conceituais, buscamos retomar o papel fundamental que o partido de caráter revolucionário cumpre no processo de ruptura com a ordem burguesa. Construímos um eixo de argumentação que situa o papel do patriarcado e do racismo no Brasil para a conformação das relações sociais capitalistas, assim como demonstramos a importância da luta antipatriarcal construída pelo movimento feminista e pelo movimento LGBT.

Esse percurso de análise nos permite observar que, conforme Saffioti $(1987 ;$ 2004) e Vinagre (2011), as lutas "particulares" devem estar mediatizadas pelas requisições da luta de classe, que pressupõe o antagonismo entre os interesses da burguesia e do proletariado. Do mesmo modo, nos permite constatar que diante da imbricação do patriarcado, do racismo e do capitalismo na formação social brasileira, é necessário que a luta mais ampla e consciente do proletariado incorpore as dinâmicas de resistência da luta antipatriarcal e antirracista. Este caminho também impõe uma questão fundamental: a percepção de que existem relações patriarcais associadas ao capitalismo influenciam na construção da tática e da estratégia revolucionária das organizações partidárias?

Diante das questões aventadas, tomamos como hipótese que a unidade entre a as lutas de classes e as lutas das mulheres, negros/as

234 Hegemonia heterossexista, lutas antipatriarcais... 
e LGBT se constituem numa potência peculiar, pois, radicaliza o projeto de emancipação do proletariado e, com isso, torna a perspectiva de emancipação humana mais plena de sentido na realidade social. Neste sentido, ao encaramos o partido como instrumento de universalização das lutas sociais (BRAZ, 2014), é fundamental um vínculo orgânico que se traduz na incorporação da luta antipatriarcal na construção de táticas e estratégias dessas organizações.

\section{Considerações finais}

A realidade social em que estamos inseridos/as, numa perspectiva materialista histórica e dialética, deve ser desvendada em suas múltiplas expressões. Propusemo-nos construir uma abordagem das relações patriarcais de gênero condizentes com a perspectiva teórico-metodológica que adotamos. Isso implicou descortinar o véu aparente que separa as relações patriarcais de gênero da problemática das classes sociais na sociedade capitalista. Ao contrário, defendemos, conforme Saffioti $(1987,2004,2013)$, que as relações sociais estão enoveladas nos seus aspectos determinantes: as relações de classe, as relações patriarcais de gênero e as relações de "raça"/etnia.

Nosso esforço é legatário de um conjunto de elaborações teóricas e lutas políticas que tem sua origem nos processos históricos de unidade do feminismo com o proletariado da Europa do século XIX. Este esforço também é fruto das sólidas parcerias entre as lutas feministas e LGBT que se desenvolveram no século XX e que se estendem aos dias atuais. Assim, as reflexões travadas aqui são parte de um processo coletivo que implica compreender o potencial dessas articulações que visam construir um projeto de completa emancipação dos seres humanos. Identificamos neste artigo que as lutas e enfrentamentos dos movimentos LGBT e feminista fizeram e ainda fazem frente às relações patriarcais de gênero e suas formas de opressão. Por isso, observamos que as lutas e a ação política desses movimentos que rememoramos na seção dois denotam um componente "antipatriarcal".

cadernos cemarx, no $10-2017 \quad 235$ 
Noentanto, partimos da premissa de que as lutas "antipatriarcais" possuem limites ontológicos ao vislumbrarem a superação das formas de dominação/exploração. Para nós, a existência das relações patriarcais de gênero - que são formas de sociabilidade que atendem os interesses da sociabilidade capitalista - são indissociáveis do modo de vida burguês. Caso as lutas "antipatriarcais" não estejam diretamente inseridas num permanente enfrentamento às amarras próprias da sociedade capitalista, é possível que tais lutas se percam entre si ou que não consigam questionar as bases que fundamentam a opressão: o capitalismo e o patriarcado.

Contudo, não é só a necessidade de construção de lutas "antipatriarcais" de caráter anticapitalista que está em questão nesta análise. O desafio posto ao projeto de emancipação do proletariado diz respeito à construção de instrumentos políticos capazes de conduzir a tomada do poder, vislumbrando erguer outra ordem social. Em "Que fazer?" Lenin faz uma distinção entre forças motrizes e forças dirigentes que contribui para pensar os limites das lutas "antipatriarcais". As forças motrizes dizem respeito ao conjunto das lutas sociais, de forma mais espontânea que podem se esvair ou evoluírem a depender a conjuntura de cada processo histórico. As forças dirigentes atuam sempre na tentativa de romperem os limites econômicos das lutas pontuais para construir uma consciência social mais ampla, vinculando aos interesses da classe trabalhadora.

Dessaforma, cabeaos partidos políticosvinculadosaoproletariado ir além dos limites das forças motrizes, configurando-se como forças dirigentes. A revolução deve ser apreendida como ação do proletariado em busca da sua própria emancipação. Ou seja, autoemancipação do proletariado mediado por instrumentos coletivos a serviço da sua própria classe (BRAZ, 2014). Neste sentido, é fundamental que no atual contexto da luta de classes o debate antipatriarcal esteja presente no âmbito dos partidos políticos proletários, contribuindo com o processo de delineamento tático e estratégico para romper as cercas do

$236 \quad$ Hegemonia heterossexista, lutas antipatriarcais... 
capital e vislumbrar outra ordem social sem dominação/exploração de classe, gênero, orientação sexual e "raça"/etnia.

\section{Referências bibliográficas}

BORRILLO, D. Homofobia: História e crítica de um preconceito. Tradução Guilherme Joao de Freitas Teixeira. Belo Horizonte: Editora Autêntica, 2010.

BRAZ, M. Partido e revolução 1848-1989. São Paulo: Expressão Popular, 2011.

"As formas atuais das lutas de classes e a questão do mediador universalizante". Revista Políticas Públicas. São Luís, Número Especial, jul. 2014, p. 143-153.

"Apresentação a Que Fazer?". In: LENIN, V. Que Fazer? Problemas candentes do nosso movimento. São Paulo: Expressão Popular, 2015.

CORNWALL, A. e JOLLY, S. "Introdução: a sexualidade é importante". In: . (Orgs). Questões de Sexualidade: Ensaios transculturais. Tradução: Jones de Freitas. Rio de Janeiro: ABIA, 2008.

DEVREUX, A-M. "A teoria das relações sociais de sexo: um quadro de análise sobre a dominação masculina". Cadernos de Crítica Feminista. Ano V, n. 4, dez. 2011.

FALQUET, J. “Mujeres, feminismo y desarrollo: un análisis crítico de las políticas de las instituciones internacionales". Desacatos, n. 11, 2003, p. 13-35. 
"Repensar as relações de sexo, "raça" e classe na globalização neoliberal”. Mediações. Londrina: UEL. v. 13, n. 1-2, Jan/Jun. e Jul/ Dez. 2008, p. 121-142.

. “O capitalismo financeiro não liberta as mulheres: análises feministas materialistas e imbricacionistas". Crítica Marxista. Campinas: CEMARX/UNICAMP. n. 36, 2013, p. 09-25.

GURGEL, T. "Feminismo e luta de classe: história, movimento e desafios teórico-políticos do feminismo na contemporaneidade". Anais do 9o Seminário Internacional Fazendo Gênero. Florianópolis, 2010.

HARVEY, D. A condição pós-moderna: uma pesquisa sobre as origens da mudança cultural. São Paulo: Ed. Loyola, 2012.

KERGOAT, D. "Dinâmica e consubstancialidade das relações sociais". Novos Estudos. CEBRAP, n. 86, março 2010.

LENIN. V. O Estado e a Revolução: o que ensina o marxismo sobre o Estado e o papel do proletariado na revolução. São Paulo: Expressão Popular, 2010.

- Que fazer? Problemas candentes de nosso movimento. São Paulo: Expressão Popular, 2015.

LUKÁCS, G. Lenin: um estudo sobre a unidade de seu pensamento. Tradução de Rubens Enderle. São Paulo: Boitempo, 2012.

Para uma ontologia do ser social II. Tradução de Nélio Schneider, Ivo Tonet e Ronaldo Fortes. São Paulo: Boitempo, 2013.

238 Hegemonia heterossexista, lutas antipatriarcais... 
MARX, K. Contribuição à critica da economia política. Tradução de Florestan Fernandes. São Paulo: Expressão Popular, 2008.

. e ENGELS, F. Manifesto Comunista. São Paulo: Boitempo, 2010.

MÉSZÁROS, I. Para além do capital: rumo a uma teoria da transição. São Paulo: Boitempo, 2011.

OKITA, H. Homossexualidade: da opressão à libertação. São Paulo: Sundermann, 2015.

PRADO, M. A. M. e MACHADO, F. V. Preconceitos contra Homossexualidades: Hierarquia da invisibilidade. São Paulo: Cortez, 2008.

SAFFIOTI, H. O poder do macho. São Paulo: Moderna, 1987.

. Gênero, patriarcado, violência. São Paulo: Perseu Abramo, 2004.

SANTOS, B. S. Pela Mão de Alice: o social e político na pós-modernidade. São Paulo: Ed. Cortez, 1996.

SIMIONATO, I. "As expressões ideoculturais da crise capitalista na atualidade e sua influência teórico-política". Serviço Social:Direitos Sociais e Competências Profissionais. Brasília: CFESS/ABEPSS, 2009.

SIMÕES, J. A. e FACCHINI, R. Na trilha do arco-íris: do movimento homossexual ao LGBT. São Paulo: Ed. Fundação Perseu Abramo, 2009 .

STERNS, P. História da sexualidade. São Paulo: Contexto, 2010.

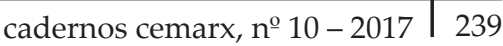


VINAGRE, M. "Diversidade humana, relações sociais de gênero e luta de classe: emancipação para além da cultura". Em Pauta: Revista da Faculdade de Serviço Social da UERJ. Rio de Janeiro, n. 28,v.9,2011, p.51-63. Disponívelem:http://www.e-publicacoes. uerj.br/index.php/revistaempauta/article/viewFile/2933/2097.

WELZER-LANG, D. "A construção do masculino: dominação das mulheres e homofobia". Tradução de Miriam Pillar Grossi. Estudos Feministas. n. 15, 2001, p. 460-482.

$240 \quad$ Hegemonia heterossexista, lutas antipatriarcais... 